\title{
PENERAPAN STUDI KONSUMSI DAN PERTUMBUHAN KURA-KURA NANAS (HEOSEMYS SPINOSA) PADA UJI KETERBACAAN BOOKLET UNTUK SISWA SMP
}

\author{
Anisah Putri Isytigfarini ${ }^{1 *}$, Aceng Ruyani ${ }^{1}$, Yennita ${ }^{1}$ \\ ${ }^{1}$ Program Studi Pendidikan Biologi, Fakultas Keguruan dan Ilmu Pendidikan, Universitas Bengkulu \\ Email: isytigfarini@gmail.com
}

\begin{abstract}
Abstrak
Penelitian ini bertujuan untuk mengetahui pengaruh konsumsi rasio pakan Carica papaya dan Musa paradisiaca terhadap pertumbuhan kura-kura nanas (Heosemys spinosa) dan untuk membuat booklet tervalidasi bagi siswa SMP. Jenis penelitian ini merupakan penelitian dan pengembangan (research and development) yang dianalisa secara deskriptif kuantitatif. Prosedur penelitian yaitu mengumpulkan data, dimulai dari a) pengamatan laju konsumsi (Consumtion rate), b) laju pertumbuhan (Growth rate) dengan parameter berupa pertumbuhan berat badan, pertumbuhan panjang karapaks, pertumbuhan lebar karapaks, pertumbuhan panjang plastron, pertumbuhan lebar plastron, pertumbuhan tebal badan, pertumbuhan panjang lengkung karapaks, dan pertumbuhan lebar lengkung setiap sisi karapaks. Dilanjutkan dengan pembuatan produk berupa: a) desain produk, b) validasi produk dan c) perbaikan desain produk. Produk yang dikembangkan adalah booklet $H$. spinosa. Dari penelitian diperoleh bahwa pakan yang paling banyak dikonsumsi adalah C. papaya dengan laju konsumsi 4,336 gr/hari. Korelasi antara laju konsumsi dengan laju pertumbuhan menunjukkan hasil positif ( $r$.hitung $>r$.tabel) dengan nilai $0,995>0,811$ untuk perlakuan A, 0,994>0,811 pada perlakuan B dan 0,995>0,811 untuk perlakuan C. Sementara itu desain produk dikoreksi oleh delapan orang validator dengan keahlian di bidangnya masingmasing. Selanjutnya Booklet yang telah tervalidasi dicetak dan diuji standar keterbacaan dengan rumus Reading Easy Score (RES). Hasil yang didapat dari perhitungan rumus RES skor keterbacaan Booklet adalah $62,42 \%$ yang berarti Booklet ini sesuai dengan standar siswa SMP.
\end{abstract}

Kata kunci : Uji keterbacaan, studi pola makan, Heosemys spinosa

\section{ABSTRACT}

This research aims to know the influence of the ratio of feed consumption of Carica papaya and Musa paradisiaca against the growth of pineapple turtle (Heosemys spinosa) and to make validation of the booklet for students of junior high school. This type of research is a research and development (research and development) which analyzed in quantitative descriptive. Research procedure that is collecting the data, starting with a) observations of the rate of consumption (Consumtion rate), b) rate of growth (Growth rate) with the parameters in the form of weight growth, growth, growth, karapaks length width karapaks, growth plastron length, plastron width growth, growth, growth, body thick long curved karapaks, and the growth of the width of the arch each side karapaks. Proceed with the manufacture of products such as: a) product design, validation, and product b) c) a repair design products. Products that are developed is a booklet of $\mathrm{H}$. spinosa. Of the research obtained that the feed the most consumed is $\mathrm{C}$. papaya with the rate of consumption of $4.336 \mathrm{gr} /$ day. The correlation between the rate of growth at a rate of consumption shows positive results ( $r$. calculate $>r$. table) with a value of 0,995 $>0,811$ for treatment $A, 0,811>0,994$ in treatment and treatment for 0,811 $>0,995 \mathrm{c}$. Meanwhile corrected by eight product design people with expertise in their field validator respectively. Further validation of the printed Booklet that has been tested and formulas with standard Reading Easy Score (RES). The results obtained from the calculation formula RES reading score Booklet was $62.42 \%$ which means this Booklet in accordance with standard junior high school students.

Keywords: test readability, dietary studies, Heosemys spinosa 


\section{PENDAHULUAN}

Melihat keadaan sistem pembelajaran yang umum saat ini, tentu belajar dalam kelas menjadi hal yang monoton dan membosankan bagi sebagian siswa. Menurut salah seorang guru pamong mahasiswa PPL (Praktik Pembelajaran Lapangan) di SMPN 11 Kota Bengkulu pada periode PPL II tahun 2015 eterbatasan media dan kreasi mengajar menjadi salah satu penyebabnya. Namun, pada kurikulum baru yang telah disosialisasikan sebelumnya, bahwa pembelajaran di kurikulum ini akan menggunakan pembelajaran berbasis ilmiah. Ini berarti guru dituntut tidak hanya menguasai materi, bahkan guru harus bisa memberikan proses dan suasana belajar yang memotivasi bagi siswanya.

Seorang guru tidak hanya dituntut untuk dapat memaksimalkan pembelajaran di dalam kelas, tapi juga harus mampu membimbing siswa agar siswa bisa mengaplikasikan hasil belajarnya di kelas ke alam dan masyarakat. Karena itu, guru juga harus mampu menghubungkan materi pembelajaran dengan keadaan yang ada di lingkungan sekitar dalam kehidupan (Kemendikbud, 2014).

Pengadaan media dan metode belajar yang baru dan unik tentu akan sangat memberikan suasana baru bagi siswa sehingga mampu meningkatkan semangat belajar siswa. Ada beberapa alternatifbahan ajar yang dapat digunakan untuk membantu meningkatkan semangat belajar siswa salah satunya booklet. Booklet ini nantinya akan berisi identitas tentang Heosemys spinosa yang dikemas dengan gambar dan warna yang sesuai dengan siswa SMP dan dilengkapi dengan soal latihan. Pengadaan booklet ini nantinya juga dapat membantu siswa dan guru untuk lebih mengenal salah satu satwa langka Bengkulu yang saat ini tengah masuk list merah atau hampir punah ini.

Populasi kura-kura yang semakin berkurang salah satu penyebabnya adalah maraknya perburuan baik untuk keperluan konsumsi maupun koleksi. Kebutuhan konsumsi akan telur kura-kura yang terbilang lezat dan sehat membuat telurnya banyak diincar dan diperjual belikan masyarakat. Hal ini menyebabkan anakan kura-kura yang seharusnya maksimal menjadi berkurang. Begitu juga dengan perburuan unuk kebutuhan koleksi dan lebih parah untuk dijadikan sebagai bahan pemenuh selera modern seperti hiasan meja, hiasan dinding, tas, sepatu dan lain sebagainya. Terlebih dalam tahun-tahun terakhir, permintaan akan sumber daya hayati seperti kura-kura sangat meningkat, terutama dari daerah China, Eropa dan Amerika Serikat, baik sebagai hewan kesayangan maupun sebagai bahan makanan eksotik. Hal ini ternyata bukan menjadi bahan konsumsi keluarga saja, tetapi juga sebagai konsumsi para peneliti asing untuk memperoleh karya ilmiah dengan cepat dan murah mengenai biota Indonesia. Sedangkan bagi penduduk lokal, menjual biota alami lokal lebih merupakan tambahan pemenuh kebutuhan hidup yang paling dasar, sedangkan para pedaganglah yang meraup keuntungan paling besar (Iskandar, 2000).

Adapun spesies yang sudah sangat terancam di Indonesia, khususnya Bengkulu ini adalah $H$. spinosa yang jumlahnya sudah sangat sedikit. Keberadaannya di IUCN juga sudah berstatus terancam punah atau endangered. Sedangkan status di CITES sudah dalam konteks Appendix II. Spesies ini merupakan spesies kura-kura yang tergolong herbivora pemakan buah-buahan. Keadaan alam yang semakin kritis dengan maraknya pembakaran hutan membuat keberadaannya di alam semakin terancam (IUCN, 2016). Penelitian ini bertujuan untuk mengetahui jenis pakan yang baik untuk memelihara $H$. spinosa mengetahui pengaruh pemberian perlakuan makan terhadapa laju konsumsi dan pertumbuhan $H$. spinosa, mengetahui tingkat keterbacaan booklet pada siswa berasrkan studi konsumsi dan pertumbuhan yang telah dilakukan. 


\section{METODE}

Penelitian eksperimen ini telah dilakukan selama 30 hari (satu bulan) mulai dari tanggal 28 Mei 2016 sampai 27 Juni 2016 di Sumber Belajar IImu Hayati (SBIH) Ruyani dan Universitas Bengkulu. Alat dan bahan yang digunakan selama penelitian adalah:

$\begin{array}{ll}\text { Keranjang plastik } & \text { : } 9 \text { buah } \\ \text { Wadah makanan } & : 9 \text { buah } \\ \text { Wadah air minum } & : 9 \text { buah } \\ \text { Pisau } & : 1 \text { buah } \\ \text { H. spinosa } & : 9 \text { ekor } \\ \text { C. Papaya } & : 15 \% \text { setiap hari } \\ \text { M. Paradisiaca } & : 15 \% \text { setiap hari } \\ \text { Air minum } & : \text { satu piring kecil per } \\ \text { individu setiap harinya } \\ \text { Prosedur Penelitian } \\ \text { 1) Pengumpulan H. Spinosa } \\ \text { 2) Pemberian tagging (pemberian nama) } \\ \text { pada tiap individu } \\ \text { 3) Pengukuran kondisi tubuh meliputi berat }\end{array}$

\begin{tabular}{|c|c|c|c|c|c|c|c|c|}
\hline \multirow{3}{*}{$\begin{array}{l}\text { Va } \\
\text { lid } \\
\text { asi } \\
\text { ke }\end{array}$} & \multicolumn{8}{|c|}{ Hasil Validasi (\%) } \\
\hline & \multicolumn{3}{|c|}{ Ahli Biologi } & \multicolumn{2}{|c|}{$\begin{array}{c}\text { Guru } \\
\text { Biologi }\end{array}$} & \multicolumn{3}{|c|}{ Siswa } \\
\hline & 1 & 2 & 3 & 1 & 2 & 1 & 2 & 3 \\
\hline 1 & 81 & 44 & 56 & 81 & 84 & 75 & 90 & 80 \\
\hline 2 & 81 & 75 & 78 & 81 & 84 & 75 & 90 & 80 \\
\hline
\end{tabular}

badan, panjang karapakss, lebar karapakss, panjang plastron, lebar plastron, tebal badan

4) Pemeliharaan

5) Penimbangan dan pemberian pakan dilakukan setiap satu minggu sekali pada hari Minggu dan untuk pemberian pakan dilakukan setiap hari pukul 10.00 WIB.

6) Desain Produk (booklet)

7) Validasi desain produk

Pengukuran laju konsumsi (Consumtion rate $=C R$ ) dianalisis dengan rumus:

$$
\mathrm{CR}=\frac{\text { berat makanan yag dimakan }(g)}{\text { durasi percobaan }(\text { jam })}
$$

Pengkuran laju pertumbuhan (Growth rate = $G R)$ dianalisis dengan rumus:

$$
\mathrm{GR}=\frac{\text { pertambahan berat }(g)}{\text { durasi percobaan (hari) }}
$$

Menghitung Reading Easy Score (RES)

dianalisis dengan rumus:

Rata-rata panjang kalimat $\times 1.015=$

Jumlah suku kata per 100 kata $\times 0.846=$ . (Wardiny, 1992

\section{HASIL DAN PEMBAHASAN}

Dari hasil validasi yang tertera pada tabel terlihat bahwa Booklet ini mengalamai revisi sebanyak dua kali. Hasil validasi dan uji keterbacaan dapat dilihat pada Tabel 1 dan Tabel 2. Hal ini terbukti karena masih ada penilaian di bawah $50 \%$ dan validasi dibawah $50 \%$ berarti Booklet masih perlu direvisi. Pada produk awal Booklet ada beberapa validator yang masih merevisi di berbagai segi tampilan dan isi Booklet. Adapun beberapa tahapan revisi yang dilakukan adalah pertama mulai dari perubahan desain cover dari yang masih polos dan acak menjadi lebih berwarna dan menggambarkan isi booklet. Kedua, penulisan isi boolet yang awalnya kurang terinci menjadi lebih terstruktur dan dilengkapi dengan daftar isi, gambar dan tabel. Ketiga, di masukkannya data-data hasil penelitian yang telah disaring kembali agar lebih mudah dipahami siswa.

Tabel 1. Hasil Validasi Booklet

Tabel 2. Hasil Uji Keterbacaan

\begin{tabular}{cccccc}
$\begin{array}{c}\boldsymbol{\Sigma} \\
\text { kata }\end{array}$ & $\begin{array}{c}\boldsymbol{\Sigma} \\
\text { kalimat }\end{array}$ & $\begin{array}{c}\boldsymbol{\Sigma} \text { suku } \\
\text { kata/10 } \\
\text { 0 kata }\end{array}$ & ASL & ASW & RE \\
\hline 1125 & 155 & 274 & 0,1 & 2,74 & $\begin{array}{c}62 \\
42 \\
\%\end{array}$ \\
\hline
\end{tabular}

Keterangan Tabel:

$R E=206,835-(1,015 \times$ ASL $)-(0,846 \times$ ASW $)$

$\mathrm{RE}=$ Keterbacaan Kemudahan

ASL (Average Sentence Long) = rata Kalimat Panjang (yaitu, jumlah kata dibagi dengan jumlah kalimat) 
ASW (Average Sentence Word) = Jumlah rata-rata suku kata per 100 kata (yaitu, jumlah suku kata dibagi dengan jumlah kata)

Untuk penggunaannya pada siswa SMP sendiri Booklet ini sudah memenuhi syarat penggunaan. Berdasarkan hasil uji keterbacaan Booklet di atas maka diketahui bahwa Booklet ini cocok untuk digunakan pada pembelajaran bagi siswa SMP dengan persentase $62,42 \%$. Dengan persetase 62,42 $\%$ yang dikategorikan standar dan bisa diterima oleh siswa SMP. Siswa SMP merupakan peralihan dari masa kanak-kanak menuju masa remaja sehingga pola pikirnyapun masih antara anak-anak dan remaja. Dalam pemikiran secara pembelajaran mereka masih membutuhkan bacaann yang selain mudah dimengerti dan tidak membosankan juga menarik serta terjangkau oleh kemampuan baca mereka.

Untuk data mengenai laju konsumsi dan laju pertumbuhan kura-kura selama tiga pekan dapat dilihat pada Tabel 3 dan Tabel 4.

Tabel 3. Rata-rata Laju Konsumsi Selama Tiga Pekan (CR=gram/jam)

\begin{tabular}{|c|c|c|c|c|c|}
\hline \multirow{2}{*}{$\begin{array}{l}\text { Perlakuan } \\
\text { Pakan } \\
\text { (10\% Berat } \\
\text { Badan) }\end{array}$} & \multicolumn{4}{|c|}{ Pekan ke- } & \multirow[b]{2}{*}{$\begin{array}{l}\text { Rata } \\
\text {-rata }\end{array}$} \\
\hline & $\mathbf{n}$ & I & II & III & \\
\hline $\begin{array}{c}\text { A }(100 \% \\
\text { C.papaya) } \\
\text { B }(50 \%\end{array}$ & 3 & $\begin{array}{c}3,6 \\
3\end{array}$ & $\begin{array}{c}4,6 \\
3\end{array}$ & $\begin{array}{c}4,7 \\
5\end{array}$ & 4,34 \\
\hline $\begin{array}{c}\text { C. papaya }+ \\
50 \%\end{array}$ & 3 & 1,3 & $\begin{array}{c}1,5 \\
6\end{array}$ & $\begin{array}{c}1,6 \\
5\end{array}$ & 1,50 \\
\hline M.paradisiaca & & & & & \\
\hline $\begin{array}{c}\text { C }(100 \% \\
\text { M.paradisiaca } \\
)\end{array}$ & 3 & $\begin{array}{c}1,7 \\
3\end{array}$ & $\begin{array}{c}0,7 \\
7\end{array}$ & $\begin{array}{c}0,8 \\
6\end{array}$ & 1,12 \\
\hline
\end{tabular}

Dari hasil tersebut, dapat dianalisis bahwa perlakuan A memberikan efek konsumsi yang lebih cepat (laju konsumsi lebih banyak dan cepat) dibanding dua perlakuan lainnya. Hal ini terbukti dari jumlah konsumsi yang cenderung lebih banyak setiap pekannya dan konsisten meningkat jumlah konsumsinya. Jumlah konsumsi yang besar pada perlakuan pertama ini membuktikan bahwa kandungan gizi yang terdapat pada C. papaya memang sesuai serta dibutuhkan dan disukai oleh kura-kura jenis $H$. spinosa ini. Serta kandungan gizi yang tercampur antara $C$. papaya dan $M$. paradisiaca justru menurunkan laju konsumsinya, hal ini membuktikan bahwa $H$. spinosa tidak menyukai perlakuan kedua yang tercampur ini. Dan pada perlakuan ketiga, laju konsumsinya juga menurun, diakibatkan adanya kandungan magnesium yang cukup tinggi pada $M$. paradisiaca yang kurang baik bagi pertumbuhan $H$. spinosa.

Tabel 4. Rata-rata Laju Pertumbuhan Selama Tiga Pekan (gram/hari)

\begin{tabular}{|c|c|c|c|c|c|}
\hline \multirow{2}{*}{$\begin{array}{c}\text { Kelompok } \\
\text { Perlakuan } \\
\text { Pakan }\end{array}$} & \multirow{2}{*}{$\mathrm{n}$} & \multicolumn{3}{|c|}{ Pekan ke- } & \multirow{2}{*}{$\begin{array}{l}\text { Rata } \\
\text {-rata }\end{array}$} \\
\hline & & I & II & III & \\
\hline $\begin{array}{c}\text { A }(100 \% \\
\text { C.papaya) }\end{array}$ & 3 & 2 & $\begin{array}{c}7,7 \\
1\end{array}$ & $\begin{array}{c}1,2 \\
4\end{array}$ & 3,65 \\
\hline $\begin{array}{c}\text { B }(50 \% \\
\text { C.papaya }+50 \% \\
\text { M.paradisiaca) }\end{array}$ & 3 & 2,9 & -2 & $-0,9$ & 0 \\
\hline $\begin{array}{c}\text { C }(100 \% \\
\text { M.paradisiaca })\end{array}$ & 3 & $\begin{array}{c}1,0 \\
4\end{array}$ & $\begin{array}{c}3,9 \\
5\end{array}$ & -5 & $\begin{array}{c}- \\
0,00 \\
3\end{array}$ \\
\hline
\end{tabular}

Dari hasil penelitian ini memperlihatkan bahwa pemberian pakan berupa Carica papaya memiliki efek positif yang lebih signifikan terhadap pertumbuhan Heosemys spinosa. Hal ini sesuai dengan kebutuhan gizi bagi H.spinosa yang juga terkandung sebagian besar dalam $C$. papaya. C.papaya mengandung vitamin $A, B$ dan $C$ serta karbohidrat, serat dan kalsium yang baik bagi pertumbuhan $H$. spinosa. Sedangkan pada perlakuan $M$. paradisiaca cenderung kurang menunjukkan perubahan signifikan dikarenakan kandungannya berupa asam folat yang tinggi dan zat besi dan berefek justru menurunkan berat badan.

Berdasarkan pengamatan selama tiga pekan terlihat bahwa setiap perlakuan 
memperlihatkan persentase pertumbuhan yang berbeda. Terlihat bahwa perlakuan yang paling menunjukkan pertumbuhan secara signifikan adalah perlakuan $\mathrm{A}$ dengan akurasi 0,56\%. Dilanjutkan dengan perlakuan $B$ dengan ajurasi $0,2178 \%$ dan yang paling menunjukkan pertumbuhan rendah adalah perlakuan $C$ dengan akurasi $0,087 \%$.

Perbedaan persentase laju pertumbuhan dapat disebabkan karena adanya jumlah konsumsi yang berbeda-beda pada setiap perlakuannya. Untuk mengetahui kemudian akan dibahas berdasarkan ada tidaknya korelasi antara laju konsumsi dengan laju pertumbuhannya.

Tabel 6. Uji Korelasi Laju Konsumsi dan Laju Pertumbuhan Selama Tiga Pekan Penelitian

\begin{tabular}{ccc}
\hline Perlakuan & Nilai $r_{\text {hitung }}$ & Nilai $r_{\text {tabel }}$ \\
\hline A & 0,995 & 0,811 \\
B & 0,994 & 0,811 \\
C & 0,995 & 0,811 \\
\hline
\end{tabular}

Berdasarkan Tabel di atas terlihat bahwa setiap perlakuan menunjukkan adanya kesinambungan antara laju konsumsi dengan laju pertumbuhan, yaitu ( $r_{\text {hitung }}>$ $\left.r_{\text {tabel }}\right)$. Seperti terlihat pada perlakuan A $(0,995>0,811)$, B $(0,994>0,811)$, dan $C$ $(0,995>0,811)$. Hasil yang positif ini membuktikan adanya korelasi antara laju konsumsi dengan laju pertumbuhan, dimana semakin banyak konsumsi maka akan semakin besar pula laju pertumbuhannya.

Dari keseluruhan terlihat penelitian ini memperlihatkan hasil yang menonjol pada kelompok perlakuan A. Hal ini sejalan dengan komposisi nutrisi yang terdapat dalam $C$. papaya di mana terdapat banyak kandungan zat besi yang sangat dibutuhkan oleh $H$. spinosa bagi pertumbuhannya. Sedangkan pada perlakuan $\mathrm{C}$, banyak menunjukkan hasil yang kurang menonjol karena adanya kandungan fosfor, yang apabila berlebih sehingga tidak membantu dalam pertumbuhannya.

\section{PENUTUP}

Simpulan

Dari penelitian ini didapatkan kesimpulan bahwa jenis pakan yang dianjurkan untuk pemeliharaan H.spinosa adalah C. papaya. Terbukti dari hasil penelitian di mana jenis pakan yang paling banyak dimakan dan disukai $H$. spinosa adalah C. papaya. Adanya korelasi positif antara laju konsumsi dengan laju pertumbuhannya. Di mana semakin banyak konsumsinya, maka semakin besar laju pertumbuhannya. Dan produk Booklet yang diterbitkan sesuai dan tervalidasi untuk digunakan pada siswa kelas VII SMP.

Saran

Disarankan selama penelitian agar lingkungan penelitian juga diperhatikan, karena $H$. spinosa termasuk kura-kura yang sensitif terhadap lingkungannya. Pemeliharaan $H$. spinosa dianjurkan menggunakan jenis pakan $C$. papaya. Penggunaan booklet sebaiknya tetap disertai dengan pengamatan lapangan beserta objek aslinya.

\section{DAFTAR PUSTAKA}

Kemendikbud. 2014. Permendikbud no 59 Tahun 2014 tentang Kurikulum 2013 Sekolah Menengah Atas/Madrasah Aliyah. Jakarta: Kemendikbud RI.

http://www.iucnredlist.org/ details/9942/0\&prearchev=s. Diakses pada Selasa, 12 April 2016 16:10.

http://zipcodezoo.com/index.php/ Heosemys_spinosa. Diakses pada Selasa, 12 April 21:25.

Iskandar, D.T. 2000. Kura-Kura \& Buaya Indonesia \& Papua Nugini. Bandung : PALMedia Citra

Wardiny, T. 1992. Laporan Penelitian Mengukur Keterbacaan Modul Pancasila. 
http://www.pustaka.ut.ac.id/pdfpen elitian/80218.pdf. Diakses pada Rabu, 13 April 2016 22:35. 